\title{
Psychological and Human Factors in Long Duration Spaceflight
}

\author{
M. Ephimia Morphew*, M.S.
}

\begin{abstract}
The spaceflight environment is characterized by temperature extremes, microgravity, solar and galactic cosmic radiation, lack of atmospheric pressure, and high-speed micrometeorites. While these factors induce a host of physiological, biomedical, and environmental stressors to flight crews, long duration spaceflight has revealed an additional group of stressors that impact crew performance and health. This paper will provide members of the medical community with a basic understanding of human-related stressors in the spaceflight environment, the effects of these stressors, and the role that the behavioral sciences (e.g., psychology, human factors, sociology, habitability) play in supporting crew health in space. Some of the current tools and methodologies used by behavioral scientists for countering spaceflight stressors and promoting crew health, productivity, and mission success will also be discussed.
\end{abstract}

\footnotetext{
"The most critical problems facing humans in long duration spaceflight, after the biomedical problems, are the psychosocial and psychological problems"

Oleg Atkov, Russian Cosmonaut (237 days aboard Salut 7, 1984).
}

\section{INTRODUCTION}

Traditionally, the development of technology has taken the forefront in our efforts to sustain life underwater, in the air, in outer space, and in complex technological environments. This is visibly illustrated in both the spaceflight and aviation domains. Our efforts in human spaceflight were first dedicated solely toward developing the technology needed to build rockets, propulsion, and engineering systems capable of delivering humans beyond Earth's atmosphere.

\footnotetext{
* To whom correspondence should be addressed: Senior Human Systems Engineer/SPACEHAB, NASA Johnson Space Center, 2101 Nasa Rd. 1, Houston, TX 77058, USA
}

Similarly, efforts in aviation were dedicated solely towards understanding the principles of aerodynamics and building aircraft structures capable of sustaining flight.

The achievement of these technological and engineering feats provided an awareness of the physiological and biomedical stressors associated with operating in these environments. Myriad physiological conditions arising from spaceflight include Space Adaptation Sickness (SAS), bone demineralization, fluid shifts, and cardiovascular deconditioning. Accordingly, the development of biomedical and physiological countermeasures was undertaken in an effort to begin overcoming these stressors. These countermeasures allow us to sustain human presence in flight for increasing periods, as well as to participate in increasingly complex and lengthy missions.

We now, however, stand on the forefront of a new challenge. Our experience in long-duration spaceflight has revealed that it is often the human element 
Table 1. Stressors of Long Duration Spaceflight

\begin{tabular}{|c|c|c|c|c|}
\hline Physiological/Physical & Psychological & Psychosocial & Human Factors & Habitability \\
\hline Radiation & Isolation \& confinement & $\begin{array}{l}\text { High team coordination } \\
\text { demands }\end{array}$ & $\begin{array}{l}\text { High \& low levels } \\
\text { of workload }\end{array}$ & $\begin{array}{l}\text { Limited } \\
\text { hygiene }\end{array}$ \\
\hline $\begin{array}{l}\text { Absence of natural } \\
\text { time parameters }\end{array}$ & $\begin{array}{l}\text { Limited possibility } \\
\text { for abort/rescue }\end{array}$ & $\begin{array}{l}\text { Interpersonal tension } \\
\text { between crew/ground }\end{array}$ & $\begin{array}{l}\text { Limited exchange of info/comms } \\
\text { with external environment }\end{array}$ & $\begin{array}{l}\text { Chronic exposure } \\
\text { to vibration and noise }\end{array}$ \\
\hline $\begin{array}{l}\text { Altered circadian } \\
\text { rhythms }\end{array}$ & $\begin{array}{l}\text { High-risk conditions \& } \\
\text { potential for loss of life }\end{array}$ & Family life disruption & $\begin{array}{l}\text { Limited equipment, facilities } \\
\text { and supplies }\end{array}$ & Limited sleep facilities \\
\hline $\begin{array}{l}\text { Decrease in exposure } \\
\text { to sunlight }\end{array}$ & $\begin{array}{l}\text { System \& mission } \\
\text { complexity }\end{array}$ & $\begin{array}{l}\text { Enforced interpersonal } \\
\text { contact }\end{array}$ & $\begin{array}{l}\text { Mission danger \& risk associated } \\
\text { with: equipment failure, } \\
\text { malfunction, or damage }\end{array}$ & Lighting \& illumination \\
\hline $\begin{array}{l}\text { Adaptation to micro- } \\
\text { gravity }\end{array}$ & $\begin{array}{l}\text { Hostile external } \\
\text { environment }\end{array}$ & $\begin{array}{l}\text { Crew factors (i.e., gender, } \\
\text { size, personality, etc.) }\end{array}$ & $\begin{array}{l}\text { Adaptation to the artificially } \\
\text { engineered environment }\end{array}$ & Lack of privacy \\
\hline $\begin{array}{l}\text { Sensory/perceptual } \\
\text { deprivation of varied } \\
\text { natural sources }\end{array}$ & $\begin{array}{l}\text { Alterations in sensory } \\
\text { stimuli }\end{array}$ & Mulitcultural issues & Food restrictions/ limitations & $\begin{array}{l}\text { Isolation from support } \\
\text { systems }\end{array}$ \\
\hline Sleep disturbance & $\begin{array}{l}\text { Disruptions in sleep } \\
\text { (readjustment with } \\
\text { crew changeovers) }\end{array}$ & "Host-Guest" phenomenon & Technology-interface challenges & \\
\hline $\begin{array}{l}\text { Space Adaptation } \\
\text { Sickness (SAS) }\end{array}$ & $\begin{array}{l}\text { Limited habitability (e.g., } \\
\text { limited hygiene) }\end{array}$ & Social conflict & $\begin{array}{l}\text { Use of equipment in } \\
\text { microgravity conditions }\end{array}$ & \\
\hline
\end{tabular}

pertaining to poor human-technology interface design, team and interpersonal dynamics, spacecraft internal environmental conditions (habitability), and psychological factors that limit successful performance during spaceflight, rather than the purely technological factors of the environment. Russian experience in long duration spaceflight has revealed that among the most critical problems facing humans in long duration spaceflight, after the biomedical, are the psychological and psychosocial (1-4; O. Jdanov, personal communication, 1996; O. Atkov, personal communication, 1996).

While experience in long duration spaceflight has demonstrated how extremely capable crews are, it has also demonstrated that if designers and mission executors do not support the human factor through good design, environmental habitability, and mission support, crew productivity, health, and mission success will suffer.

"I think [psychological issues] is going to be one of the major findings of this mission [Mir 18 (Norm Thagard)]. If we expect to send people on missions of two or three years, we darn well better deal with the psychological aspects in addition to the physiological ones. This hasn't been our tendency in the past."

NASA Administrator, Dan Goldin
These findings regarding spaceflight mission success have been revealed in aviation operations as well. In fact, it has now been established that over $70 \%$ of all aviation accidents occur because of human and crew-related factors (5).

It is important to understand that the above statistic does not indicate that the fault be placed on aviation crews themselves, rather, that crew-related errors are a result of factors like poor cockpit design, poor design of communication protocols among and between crewmembers and flight controllers, stress-related factors, fatigue, and training.

\section{STRESSORS IN THE SPACEFLIGHT ENVIRONMENT}

Table 1 gives a brief overview and classification of the psychological, physiological, physical, and psychosocial stressors characterizing the long-duration spaceflight environment. The items appearing in this table were generated from the author's review of relevant research, discussion with astronauts and cosmonauts, and training in spaceflight psychology and habitability at NASA Johnson Space Center (JSC) and the International Space University. It must be noted that many items are not mutually exclusive, and can fit appropriately into multiple classifications (e.g. adaptation to microgravity is a physiological, as well as psychological stressor). 
While a full discussion of each stressor listed in Table 1 is beyond the scope of this paper, the author will address a select few for discussion.

\section{Isolation and Confinement}

Isolation and confinement pose a challenge to the performance of crews living and working in environments including spaceflight and polar stations $(4,6)$. Crews preparing for upcoming International Space Station (ISS) flights will serve 4-6 month tours aboard the Station. A variety of psychological and physical effects have been noted from both operational and simulated isolated and confined environments. Examples include motivational decline, fatigue, somatic complaints (e.g. insomnia, headaches, digestive problems), and social tensions (6-10). Strained crew relations, heightened friction, and social conflict are expected correlates of isolation and confinement, as is found in long duration spaceflight $(9,11)$.

\section{Physiological and Physical Adaptation to Microgravity}

Physiological stressors inherent in the long-duration space environment pose the greatest challenge to human spaceflight. The human body must physically adapt to the foreign microgravity environment and, in doing so, undergo cardiovascular, muscular, and skeletal deconditioning as well as changes in the immune and nervous systems, and radiation exposure. Regarding the physical effects of adaptation to spaceflight, about $40-50 \%$ of flight crews during their first few days of microgravity experience a condition called Space Adaptation Sickness (SAS), which causes symptoms such as nausea, disorientation, headache, and a sea-sick or flu-like feeling. Some of the above named factors can be alleviated by exercise and pharmacological interventions, but others remain a significant obstacle to maintaining the health of astronauts during long duration missions.

Similarly, crews must undergo the stress associated with re-adapting to the 1 -g environment upon return to Earth. These physiological factors are a significant concern for a human mission to Mars. These and other adaptive physiological and physical processes represent change from a normal state of functioning for the astronauts and can thus contribute to increased psychological stress levels.

\section{Psychological and Interpersonal Stressors}

Russian and American experience has revealed the importance of the psychosocial or interpersonal stressors associated with long-duration spaceflight $(9,12-14)$. Because the ISS will eventually be staffed by astronauts from different nations, interpersonal and psychosocial issues will become even more salient due to heterogeneous crews with differences in nationality, religion, social values, and political beliefs. Relating to the psychosocial aspects of crew performance in spaceflight, Santy and colleagues (15) conducted an international shuttle crew debrief on the impact and number of pre-flight, in-flight, and postflight incidences related to multicultural factors. Results showed that for nine US astronauts who flew on ISS missions, forty-two incidents were reported (nine during pre-flight, twenty-six in-flight, and seven in the post-flight period). Astronauts rated the majority of these incidences as having low or medium impact, but five of the in-flight incidents were rated as having a high mission impact. Such incidents are indicative of the importance of developing an awareness of the psychosocial factors that affect productivity, well-being, and performance of crews, particularly for operations aboard ISS. For a review of multicultural issues in long duration spaceflight, see Kring, 2001 (27).

\section{THE EFFECTS OF STRESSORS ON FLIGHT CREWS}

The psychological and performance aspects of spaceflight are of particular importance at this point in time because of the deployment of ISS operations. While few performance decrements have been noted to occur during short missions (7-12 days), longer duration flights (4+ months) have revealed a tendency for astronauts to develop symptoms of cumulative fatigue and asthenia (16). Asthenia is generally characterized by abnormal fatigue, weakness, emotional lability, irritability, and minor disorders of attention and memory (16). Although these symptoms rarely reach clinical levels, they have resulted in instances of impaired performance capacity, significant conflict among crew members, and errors in performing operational tasks $(17,18)$, thus constituting a risk factor for the safety and functioning of crewmembers (16), as well as mission success.

A brief list of the major categories of symptoms that can be experienced during long duration spaceflight is included in Table 2. For a more thorough overview of the psychological, behavioral, and psychiatric effects of long duration spaceflight, see references 3 and 16 . It should be mentioned that many of these effects do not result from properties inherent in the space environment itself, rather, most of these effects arise from the properties of the space mission environment (as are characterized above in Table 1). The space mission environment is defined 
in great part by mission planners, engineers, and a plethora of environmental, political, temporal, financial, and engineering constraints. The exception involves the physiological, neurophysiological, and biomedical detriments that are directly attributable to the effects of microgravity on the human body.

\section{DISCIPLINES AIMED AT SUPPORTING PERFORMANCE IN SPACEFLIGHT}

In the last several decades, several academic disciplines are being applied to spacecraft operations including psychology, habitability, human factors, sociology, and performance. A brief description of each discipline's efforts in these areas will be discussed.

\section{SPACE PSYCHOLOGY}

The newly emerging discipline of space psychology involves the application of psychological and behavioral principles to the support of crew health and well-being before, during, and after space flights. Dr. Albert Holland, Chief of Psychological Support at NASA JSC in Houston, Texas, has been supporting crews and their families for over 15 years (see reference 14).

The experience of Russia and the US in long duration spaceflight has revealed the need for psychological countermeasures to support human crews in space and facilitate their resistance to the stressors of spaceflight. Accordingly, countermeasures are being developed, validated, and implemented, which aim to lessen the impact of these stressors on crews and subsequently increase mission safety and success while lowering risk. Psychological countermeasures involve astronaut selection, training, and in-flight support. Such countermeasures are currently being employed in varying degrees, by Russian, European, Japanese, Canadian, and US space programs in an effort to overcome the stressors of spaceflight.

\section{Psychological Selection}

Methods are currently being developed and validated which attempt to select-in psychologically fit crewmembers, as opposed to only selecting-out psychiatrically ill applicants (the latter being the method traditionally used throughout manned spaceflight history). The Behavior and Performance group at NASA JSC is currently validating a psychological select-in astronaut selection methodology (19). These validation studies have now revealed that several personality variables such as agreeableness, conscientiousness, empathy, sociability, and flexibility, among others, are positively correlated with astronaut performance under stressful conditions, teamwork, group living, motivation, and decision making.

\section{Psychological Training}

Psychological training focuses on developing skills for coping with the stressors of the spaceflight environment and for interacting with fellow crewmembers as well as with ground control personnel. The training also deals with leadership styles, multi-cultural issues, working in an isolated and confined environment, and communicating with team members (see reference 14 for a description of psychological training methods).

\section{In-Flight Support}

In-flight psychological support involves: 1) groundbased monitoring of the psychological, cognitive, and emotional state of crewmembers by flight psychologists and psychiatrists, 2) the provision of entertainment (e.g. videos, books, games, special items), leisure activities, and opportunities to communicate with the ground (i.e. with family and loved ones), and 3) care of the families of astronauts on the ground to help compensate for the effects of a missing spouse or parent created by the astronaut's absence. For example, long duration spaceflight crews during the Mir Phase I flights have been known to comment that the care packages sent to them on-orbit were extremely uplifting.

The critical role that psychology plays in supporting long duration spaceflight was revealed to the US during the Mir Phase I missions (for a review, see reference 4).

\section{SPACE HABITABILITY}

Operational habitability refers to the design, integration and support of human, machine, mission, and environmental elements that promote optimal performance, physical and psychological health, and safety in long duration spaceflight. Habitability pertains to the qualities of a mission that enable people to live and work in a safe and productive manner. Habitability specialists at NASA JSC provide support in the following areas: architecture, acoustics, clothing, command structure, communications, crew interface/displays, dining, environmental conditions, emergency, exercise, EVA, fatigue, equipment, food \& nutrition, group interaction, housekeeping, hygiene, lighting, maintenance, multicultural issues, psychological effects, privacy, recreation, restraints, supplies/provisioning, scheduling, sleep, stowage, translation/mobility, trash, training, and waste collection. 
Table 2. Effects of Long Duration Spaceflight on Crew Performance \& Functioning

\begin{tabular}{l}
\hline 1. Exhaustion \& Asthenia: \\
Fatigue, feeling of tiredness \\
Emotional instability \\
Sleeplessness \\
Sharpening of Personality \\
Incapacity for work \\
Disruption in psychophysiological reaction \\
Psychosomatic Dysfunction \\
2. Euphoria \\
3. Depression \\
4. Neurosis \\
5. Accentuation of negative personality traits \\
6. Cognitive effects: \\
Psychomotor performance \\
Dual-task performance \\
Tracking performance \\
Fine manual control \\
Sleep-decrement induced cognitive factors: \\
Alertness \\
Vigilance \\
$\quad$ Response Time \\
Ability to Focus
\end{tabular}

Some areas recently studied by the Operational Habitability Team at JSC include 1) the need for windows in spacecraft, 2) astronaut disorientation in long duration spaceflight, 3) the importance of group dining in long duration spaceflight, and 4) specifications for a minimum clearance for crew movement through spacecraft modules. See references 21-24 for more about spaceflight habitability and its relation to performance in space.

\section{SPACE HUMAN FACTORS}

While there are about as many definitions used to define the discipline of 'Human Factors' as there are astronauts in the astronaut corps, the discipline of human factors always involves the study of the interface between humans and technology. An example of a human factors issue would be the determination of what kind of alarm to place in an aircraft cockpit so that a pilot could distinguish it as critical and notice it among all the other alarms that periodically go off inside an aircraft cockpit. Research has demonstrated that a female voice is highly salient and noticed more frequently by pilots than simple tones. Human factors psychologists and engineers apply the principles by which humans operate (e.g. hand-eye coordination (psychomotor), cognitive, information processing and memory capabilities, etc.) to the intelligent design of a machine or tool with which humans must work.

\section{Example of a Human Factors Challenge}

One human factors challenge currently facing human factors psychologists at NASA JSC involves the design of an ISS emergency crew escape system (25). Factors like disorientation and the acute effects of stress would likely be involved in an emergency escape. Other factors that will affect the design of an escape system include unfamiliarity with the task, time pressure, poor signal-to-noise ratio, poor humansystem interface, irreversibility of errors, information overload, negative transfer between tasks, crew mismatch, hostile environment, work over/underload, and changes in ISS configuration (e.g. addition of new modules or addition/movement of escape vehicles to new/different docking ports).

These factors thus necessitate clearly discernible indicators (e.g. navigation signs and directional indicators) for multiple egress paths to the different vehicles from any location within the Station. The challenge is to design such indicators so that they are visible under challenging conditions (e.g. smoke, low illumination), serve to reorient the crewmember should he be disoriented, provide the crew with a clear and unambiguous knowledge of the path for escape, and do so in a manner that acknowledges that crewmembers may be affected by panic or acute stress factors at the time.

In the aerospace environment, good interfaces become critical because humans depend on the proper function of systems and controls for their lives. The challenge of designing good interfaces is heightened by anticipating conditions under which human-technology interaction will be strained such as during emergency situations or when the user is chronically stressed by other factors such as those listed in Table 1.

\section{SPACE SOCIOLOGY}

The study of space sociology, or psychosocial issues, involves the application of sociological principles to spaceflight. Space sociology includes the way that team members of a space mission interact with each other, the factors that influence team interactions, and how this interaction ultimately affects the outcome of the mission. In high-stress environments where crews must rely on each other to enable mission functions, factors such as the personality, gender, and multiculturality of the crewmembers impact crew performance and mission success. Team factors have at times caused the failure of missions in various extreme environments (26). Generally, sociological or interpersonal factors become particularly important in long duration spaceflight (for reviews, see references 13, 16 and 26). 
Some space psychologists have designed countermeasures aimed at supporting interpersonal interactions (1). See also the discussion above under Psychological and Interpersonal Stressors. Dr. Nick Kanas is a psychiatrist at the San Francisco VA Memorial Hospital who has done extensive research in this area.

\section{SPACEFLIGHT PERFORMANCE}

Spaceflight performance involves the study of the affects of microgravity and the spaceflight environment on an individual's cognitive, information processing, memory, psychomotor, and physical capabilities (see attributes listed in Table 2). Research has found that for the most part, the microgravity environment itself does not lead to any notable performance changes, with the exception of psychomotor (hand-eye) coordination during adaptation to microgravity ( first 2 weeks), and readaptation to Earth ( 1-2 weeks). A separate issue which has not been, but must be addressed is that even though the micro-gravity environment itself does not lead to significant performance changes, the operational mission environment can and often does. The operational mission environment includes the conditions in which the crew must operate. The characteristics of the operational mission environment can include periods of exceptionally high workload, fatigue, chronic noise, stress, temperature changes, lack of privacy, and isolation. These factors can and often have produced performance changes. Given the realization of these factors as characterizing the mission environment at times, space psychologists work to design support systems and countermeasures that will aid crewmembers when these effects are experienced.

\section{CONCLUSION}

Long duration spaceflight has revealed a multitude of psychological, physiological, psychosocial and environmental-interface challenges to crews operating within them. The US space program is now acknowledging that psychological factors are critical for supporting the health, well-being, and performance of flight crews and increasing mission safety and success. Accordingly, new areas of specialty within the behavioral sciences are emerging including space psychology, space human factors, space habitability, space performance, and space sociology. Health and medical professionals supporting human spaceflight operations will benefit from knowledge in these areas.

\section{REFERENCES}

1. Manzey D, Schiewe A, Fassbender C. Psychological countermeasures for extended manned spaceflights. Journal of
Human Performance in Extreme Environments 1995; 35: 39 60.

2. Herring L. Astronaut draws attention to psychology [communication]. Journal of Human Performance in Extreme Environments 1997; 2: 42-47.

3. Manzey D, Lorenz B. Human performance during prolonged space flight. Journal of Human Performance in Extreme Environments 1997; 2: 68.

4. Morphew ME, MacLaren S, Herring L, et al. Voyage of discovery: American astronauts aboard Russia's Mir Space Station. Journal of Human Performance in Extreme Environments 1997; 2: 39-61.

5. Weigmann DA, Shappell SA. Human factors analysis of postaccident data: applying theoretical taxonomies of human error. International Journal of Aviation Psychology 1997; 7: 67-81.

6. Palinkas LA, Johnson JC, Boster JS, Houseal M. Longitudinal studies of behavior and performance during a winter at the South Pole. Aviation, Space \& Environmental Medicine 1998; 69: 73-77.

7. Connors M. Living Aloft: Human Requirements for Extended Spaceflight. NASA Ames Research Center; Moffett Field, 1985. (Technical Report SP-483).

8. Christensen JM, Talbot JM. A review of the psychosocial aspects of spaceflight. Aviation, Space \& Environmental Medicine 1986; 57: 203-212.

9. Kanas N. Psychological, psychiatric and interpersonal aspects of long-duration space missions. Journal of Spacecraft \& Rockets 1990; 27: 457-63.

10. Ikegawa M, Kimura M, Makita K, Itokawa Y. Psychological studies of a Japanese winter-over group at Osuka Station, Antarctica. Aviation, Space \& Environmental Medicine 1998; 69: 452-460.

11. Nicholas JM. Small groups in orbit: group interaction and crew performance on space station. Aviation, Space \& Environmental Medicine 1987; 58: 1009-1013.

12. Penwell LW. Problems of intergroup behavior in human spaceflight operations. Journal of Spacecraft \& Rockets 1990; 27: 464-470.

13. Kozerenko OP, Gushin VI., Sled AD, Efimov VA, Pystinnikova JM. Some problems of group interaction in prolonged space flights. Journal of Human Performance in Extreme Environments 1999; 4: 123-127.

14. Holland A. Psychology of spaceflight. Journal of Human Performance in Extreme Environments 2000; 5: 4-20.

15. Santy PA, Holland AW, Looper L Marcondes-North R. Multicultural factors in the space environment: Results of an International Shuttle crew debrief. Aviation, Space \& Environmental Medicine 1993; 64: 196-200

16. Myasnikov VI, Zamaletdinov IS. Psychological states and group interactions of crew members in flight: In Huntoon CS, Antipov VV, Grigoriev AI. Space Biology \& Medicine, Humans in Spaceflight Book 2. Moscow: Nauka Press; 1996.

17. Nechayev AP, Isayev GF, Bronnikov SV. Ergonomic aspects of the quality analysis of spacemen's professional activity on long space flight [abstract]. 9th International Man in Space Symposium, Cologne, Germany, International Academy of Astronautics, 1991; 37.

18. Shaposhnikov YeA, Malinkina YuA, Rudometkin NM, Gerasimovich AA. Selected conclusions from psychoneurological monitoring of the status of cosmonauts on space station Mir. 24th Meeting of the Working Group on Space Biology and Medicine, Moscow, 1991; 49-50.

19. Galarza L, Holland AW, Arvey RD, et al. Identifying psychological predictors of astronaut adaptation to long duration space missions. Proceedings of the Aerospace Medical Association Annual Meeting, Detroit, MI; 1999.

20. Whitmore M, McQuilkin M. Habitability and performance 
issues for long duration space flights. Journal of Human Performance in Extreme Environments 1998; 3: 64-74.

21. Novak JB. Human engineering and habitability: the critical challenges for the International Space Station. Aviation, Space \& Environmental Medicine 2000; 71: A117-A121.

22. Stuster J. Bold Endeavors. Annapolis, Maryland: Naval Institute Press; 1996.

23. Special Issue on the International Workshop on Human Factors in Space. Aviation, Space \& Environmental Medicine Journal 2000; 71: Section II.

24. Smart K. Considerations in Crew Rescue from the ISS. Journal of the British Interplanetary Society 2001; 54.

25. Bishop SL. Team dynamics analysis of the Huautla cave diving expedition: a case study. Journal of Human Performance in Extreme Environments 1998; 3: 37-41.

26. Sandal GM. The effects of personality and interpersonal relations on crew performance during space simulation studies. The International Journal of Life Support and Biosphere Science 1999; 5: 461-490.

27. Kring J. Multicultural issues for long duration spaceflight. Journal of Human Performance in Extreme Environments 2001; 5: 11-32.

Ephimia Morphew is a Senior Engineer for SPACEHAB at NASA Johnson Space Center, working in the areas of spaceflight Operational Habitability, Human Factors, and Performance. She is the Founder and President of the Society for Human Performance in Extreme Environments, and Chief Editor for its peer-reviewed scientific journal, The Journal of Human Performance in Extreme Environments (JHPEE). She Chaired the United Nations (UN) UNISPACE III Space Generation Forum in Vienna, Austria, in July of 1999, which resulted in the United Nations' world-wide implementation of five recommendations aimed at unifying the world's efforts for peaceful uses of outer space. She is a 1996 graduate of the International Space University (ISU) in Vienna, Austria, and a graduate of the University of Illinois with a M.S. in Aerospace Human Factors \& Engineering Psychology. In 1999, she received the Aerospace Medical Association's Presidential Citation Award. 